\title{
Optimum sustainable mix proportions of high strength concrete by using Taguchi method
}

\author{
M.A. Warda, H.S. Khalil, Seleem S. E. Ahmad \\ Materials Department, Faculty of Engineering, University of Zagazig, Egypt \\ mamabowarda@gmail.com, http://orcid.org/0000-0001-2345-6789 \\ hossamkbalil_m@yahoo.com, http://orcid.org/0000-0002-2345-6790 \\ seleemabmad62@yahoo.com,bttp://orcid.org/0000-0002-2345-6791
}

\author{
I.M. Mahdi \\ Structural Eng. and Construction Management Dept., Future University, Egypt \\ ibrabimmabdi@gmail.com, bttp:/ / orcid.org/0000-0003-2345-6792
}

\begin{abstract}
In this study, mix proportion parameters of high strength concrete (HSC) were analyzed by using the Taguchi's experiment design methodology for optimal design. For that purpose, mixtures are designed in a $\mathrm{L}_{27}$ orthogonal array with six factors, namely, 'Silica Fume', 'Steel Fiber', 'Super-Plasticizer', 'Maximum Aggregate Size (AG)', 'Water / cementitious material (W/C) ratio', 'Fly Ash'. The mixtures were extensively tested to meet technical requirements of HSC. The experimental results were analyzed by using the Taguchi experimental design methodology. The best possible levels for mix proportions were determined for maximization of compressive strength at $7,28,56,90$ days, splitting tensile strength at 28 days, flexural strength at 28 days, and the slump. Also the best possible levels for mix proportions were determined for minimization of the production cost. It was found that steel fibers and fly ash are the most dominant factors in the process of optimization. The advantage of using steel fiber and fly ash was the reduced energy and cost associated with the raw materials which meant more sustainable concrete could be attained. It was also found that there is a necessity to apply a multi- response optimization to get the best mix proportions.
\end{abstract}

KEYWORDS. High strength concrete; Taguchi method; Optimal mix design.

\section{OPEN ACCESS}

Citation: Warda, M. A., Khalil, H.S., Ahmad S.S.E., Mahdi, I.M., Optimum sustainable mix proportions of high strength concrete by using Taguchi method, Frattura ed Integrità Strutturale, 54 (2020) 211-225.

Received: 16.04 .2020

Accepted: 27.08 .2020

Published: 01.10.2020

Copyright: (C) 2020 This is an open access article under the terms of the CC-BY 4.0, which permits unrestricted use, distribution, and reproduction in any medium, provided the original author and source are credited.

\section{INTRODUCTION}

lam et al., [1] in their research illustrated that the countries need to create a healthy and sustainable economy to achieve sustainable development (SD). The industries policymakers are now making the concept of SD as an important objective [2]. WCED [3] defined SD as development that meets the demand of the present generations 
without arbitrating the future generations to meet their demands. Nowadays, the SD has been the subject of discussion and debate within government, non-government, and academic circles, leading concentration of national and international economy, social and environmental agendas [4]. Hence, SD can be viewed as the satisfaction of present needs without compromising the ability of future generations to meet their own needs. Sustainability is referred to as the triple bottom line (TBL) of an organization [5], which includes the three dimensions: environment, economic and social [6] and [7]. It also promotes by giving an opportunity to create occupant friendly buildings and environment responsible ones [6]. Concrete sustainability is still a hot topic in spite of progress achieved in this area because of concrete industry still faces challenges. Several evaluation methods have been proposed in responses to these challenges, but the lack of a complete framework for sustainable concrete material remains. Because of these issues, the strategy of this research is to reduce the level consumption of resources to utilize it for present and future needs. This means reaching to an optimum of mix proportions for high strength concrete. In detection of achieving this objective, sustainable concrete is found as the best key to avoid depletion of resources. Sustainable material selection is found as a vital strategy in construction.

High strength concrete (HSC) is considered to be a concrete having a high strength at 28 days (typically greater than 40 $\mathrm{MPa}$ compressive strength or a low water / cement ratio (less than 0.35)). In order to reach high strength levels using a regular water reducer, the concrete composition had to be very carefully optimized and a stringent quality control program had to be implemented. The idea was conceived to produce the highest possible compressive strength through lowering the water / binder ratio as much as possible. The direct measurement of the tensile strength of usual concrete is not easy because of the complicated set-up that must be used. Therefore, tensile strength is usually calculated using indirect measurements, such as the measurement of the modulus of rupture (MOR) (ASTM C78) and/or the splitting tensile strength (ASTM C496). Performing the MOR and splitting tensile strength measurements does not present any special difficulties in the case of high strength concrete, so that the same set-ups and procedures used for usual concrete can also be used for high strength concrete.

When Bouygues of France decided to cast the prefabricated box girders for the Ile de Re bridge with 70 MPa concrete instead of the design $40 \mathrm{MPa}$, the unit-cost increase per cubic meter of concrete was small compared with the savings resulting from faster casting, [8]. Choosing high performance concrete for two union square in Seattle was based more on high elastic modulus than high strength, even though these two properties are somewhat related. The high elastic modulus was required to increase the building rigidity to dampen swaying in high winds. The top of the Empire state building sways about two feet $(600 \mathrm{~mm})$ during a storm, [9]. High performance concrete not only reduces the dead load of offshore platforms but also ensures outstanding durability, especially in the critical splash zone, where it is subjected to very severe exposure (this was the case for the Hibernia offshore platform in Canada), [8].

Several researchers studied mechanical properties of concrete by using Taguchi method. Ozbay et. al. [10], analyzed mix proportion parameters of high strength self-compacting concrete (HSSCC) by using the Taguchi's experiment design methodology for optimal design. Khiabani et. al. [11], presented the results of the effect of high temperatures on the retained mechanical properties of High Strength Concrete (HSC) using Taguchi method. They found that the water to binder ratio is the most important factor in mix proportion in both compressive and tensile strength. Hashemi et. al. [12], investigated optimizing mix proportions using Taguchi method. They concluded that Taguchi method has a powerful potential for estimating optimum mix-design of HSC. Also they concluded that Taguchi method saves energy, cost and time by reducing number of experiments. Emara et. al. [13] investigated the effect and optimization of using selfcompacting rubberized concrete by using Taguchi method. Their study considered examining the influence of different concrete mix proportioning parameters that included fine rubber, coarse rubber, fly ash and viscocrete contents on the studied mechanical and fresh properties. Kumari et. al. [14] optimized the cement content in concrete using pozzolanic materials as reduction of $\mathrm{CO}_{2}$ released during the production of cement is major issues of construction industry. Their study showed that both mineral and chemical admixtures can be effectively used to reduce the cement content in concrete. Tan et. al. [15] investigated the effect of the bentonite (B), fly ash (FA), and silica fume (SF) on the bleeding of cement-based grouts. The optimum conditions were determined for three different water to solids ratios. They found that silica fume is the most effective factor for bleeding. Also they observed that to reduce the bleeding in grout mixes and to carry out a successful injection it is useful to use silica fume and bentonite. Hinislioglu et. al. [16] optimized the early flexural strength of concrete pavement (CP) by using the Taguchi Method. They found the optimum conditions to be 0.35 water / cementitious ratio, gradation with minimum content of fine aggregates, $5 \%$ Fly ash content, and $0 \%$ silica fume content at 7 days curing. Maximum flexural strength of $5.31 \mathrm{MPa}$ was achieved at the optimum conditions.

In this study, 27 different mixes were produced according to aforementioned HSC concrete criteria. The experimental work was so designed that the experiments gave the best possible working conditions of the parameters that affect the mechanical properties, using the Taguchi method. In this research, 40-84 Mpa 28 days compressive strength concrete samples were produced according to the high strength concrete properties. Not only, compressive strength at 28 days, but 
also compressive strength at 7 days, compressive strength at 56 days, splitting tensile strength at 28 days, flexural strength at 28 days, production cost, and slump were considered. The experimental results were analyzed according to the Taguchi method. Using Taguchi method, mix proportions were set to best possible levels for the maximization of compressive strength, splitting tensile strength, flexural strength, and slump results. Also mix proportions were set to their best possible levels for the minimization of production cost.

\section{METHODOLOGY}

\section{Taguchi Method}

7 he Taguchi method reduces the number of trials by design of experiments. The number of possible trials for $\mathrm{P}$ parameter at $\mathrm{L}$ level as per factorial method design is $\mathrm{N}=\mathrm{L}^{\mathrm{P}}$ where $\mathrm{L}=$ number of levels for each factor and $\mathrm{P}=$ number of factors involved. For example, if we have 6 parameters at 3 levels then total number of combinations $=$ $3^{6}=729$ but with the help of Orthogonal Array $(\mathrm{OA})$, a minimum number of trials for these combinations is required. In an experimental study, in order to determine the effects of various factors, which are affecting the results of experiments, different methods and approaches are used. The fundamentals of these methods are the full factorial design and fractional factorial design. In the traditional approach, which is also known as full factorial design, the experiments are performed for each condition, which consists of all factors. In the experiments where the number of factor and their levels are few, the full factorial experimental design may be applied to the design.

Dr. Taguchi started to develop new methods to optimize the process of engineering experimentation in Japan after World War II. He developed techniques which are known as the Taguchi method [17]. With this method, which can be applied easily by the researcher, the results obtained are possible to be standardized. Standard tables known as orthogonal arrays $(\mathrm{OA})$ are used for the design of the experiments in the Taguchi method. An OA with a three level and six factors are shown in Tab. 1. This $\mathrm{OA}$ is particularly designed with the symbol of $L_{27}$. Each row in the array represents a trial condition with the factor levels, which are indicated by the numbers in the row. The columns correspond to the factors specified in the study and each column contains nine level 1, nine level 2 and nine level 3 conditions (a total of 27 conditions) for the factors assigned to the column. Thus, the evaluation of results has been standardized by this method, which can easily be applied by researchers. Taguchi method uses the $S / N$ ratio (signal-to-noise), which is a performance characteristic, instead of the average value to interpret the trial result data into a value for the evaluation characteristics in the optimum setting analysis. This ratio expresses the scatter around a target value. There are three categories of performance characteristics; the larger-the better, the smaller-the better and the nominal-the better. These performance characteristics are evaluated by using the following equations; Larger the better

$$
S / N=-10 \log _{10}\left(\frac{1}{n} \sum_{i=1}^{n} \frac{1}{Y_{i}^{2}}\right)
$$

smaller the better

$$
S / N=-10 \log _{10}\left(\frac{1}{n} \sum_{i=1}^{n} Y_{i}^{2}\right)
$$

and the nominal the better

$$
\mathrm{S} / \mathrm{N}=-10 \log _{10}\left(\frac{1}{n} \sum_{i=1}^{n}\left(Y_{i}-Y_{o}\right)^{2}\right)
$$

, where $S / N$ are performance statistics, defined as the signal to noise ratio $(S / N$ unit: $\mathrm{dB}), \mathrm{n}$ is the number of repetitions for an experimental combination, and $Y_{i}$ is a performance value of the $i$ th experiment and $Y_{0}$ is the nominal value desired. From DoE (Design of Experiment), the present work utilized orthogonal array to study the following six variables:

- Silica Fume (S.FUME)

- Steel Fiber (S.FIBER) 
- Super-plasticizer (SP)

- Maximum Aggregate Size (AG)

- Water to Cementitious Materials Ratio (W/C)

- Fly-Ash

\begin{tabular}{|c|c|c|c|c|c|c|}
\hline Mix No. & S.FUME & S.FIBER & $\mathrm{SP}$ & $\mathrm{AG}$ & $\mathrm{W} / \mathrm{C}$ & $\begin{array}{l}\text { FLY } \\
\text { ASH }\end{array}$ \\
\hline & A & B & $\mathrm{C}$ & $\mathrm{D}$ & $\mathrm{E}$ & $\mathrm{F}$ \\
\hline 1 & 1 & 1 & 1 & 1 & 1 & 1 \\
\hline 2 & 1 & 1 & 1 & 1 & 2 & 2 \\
\hline 3 & 1 & 1 & 1 & 1 & 3 & 3 \\
\hline 4 & 1 & 2 & 2 & 2 & 1 & 1 \\
\hline 5 & 1 & 2 & 2 & 2 & 2 & 2 \\
\hline 6 & 1 & 2 & 2 & 2 & 3 & 3 \\
\hline 7 & 1 & 3 & 3 & 3 & 1 & 1 \\
\hline 8 & 1 & 3 & 3 & 3 & 2 & 2 \\
\hline 9 & 1 & 3 & 3 & 3 & 3 & 3 \\
\hline 10 & 2 & 1 & 2 & 3 & 1 & 2 \\
\hline 11 & 2 & 1 & 2 & 3 & 2 & 3 \\
\hline 12 & 2 & 1 & 2 & 3 & 3 & 1 \\
\hline 13 & 2 & 2 & 3 & 1 & 1 & 2 \\
\hline 14 & 2 & 2 & 3 & 1 & 2 & 3 \\
\hline 15 & 2 & 2 & 3 & 1 & 3 & 1 \\
\hline 16 & 2 & 3 & 1 & 2 & 1 & 2 \\
\hline 17 & 2 & 3 & 1 & 2 & 2 & 3 \\
\hline 18 & 2 & 3 & 1 & 2 & 3 & 1 \\
\hline 19 & 3 & 1 & 3 & 2 & 1 & 3 \\
\hline 20 & 3 & 1 & 3 & 2 & 2 & 1 \\
\hline 21 & 3 & 1 & 3 & 2 & 3 & 2 \\
\hline 22 & 3 & 2 & 1 & 3 & 1 & 3 \\
\hline 23 & 3 & 2 & 1 & 3 & 2 & 1 \\
\hline 24 & 3 & 2 & 1 & 3 & 3 & 2 \\
\hline 25 & 3 & 3 & 2 & 1 & 1 & 3 \\
\hline 26 & 3 & 3 & 2 & 1 & 2 & 1 \\
\hline 27 & 3 & 3 & 2 & 1 & 3 & 2 \\
\hline
\end{tabular}

Table 1: A three-level orthogonal array $\left(L_{27}\right)$.

The levels and values for the considered parameters are shown in Tab. 2 and 3. According to the parameters and their variation levels, L27 orthogonal array is used. Tab. 3 shows the defined mix proportions.

\begin{tabular}{ccccccc}
\hline Levels & $\begin{array}{c}\text { S.FUME } \\
\%\end{array}$ & $\begin{array}{c}\text { Steel } \\
\text { Fiber } \%\end{array}$ & SP \% & AG (mm) & $\begin{array}{c}\text { W/C } \\
\text { Ratio }\end{array}$ & $\begin{array}{c}\text { Fly-Ash } \\
\%\end{array}$ \\
1 & 0 & 0 & 0.3 & 20 & 0.27 & 0 \\
2 & 5 & 1 & 0.5 & 14 & 0.31 & 10 \\
3 & 10 & 2.5 & 0.7 & 10 & 0.35 & 20 \\
\hline
\end{tabular}

Table 2: Mix parameters and levels.

\section{Materials}

The cement used in this research was SINAI@ CEM I 52.5N. Fineness of the Cement as shown in Tab. 4 and Cement setting time test is shown in Tab. 4 also. Also compressive strength for used cement is shown in Tab. 6 and 7. Steel fibers 
were supplied from Nassar Group ${ }^{@}$. Their aspect ratio is equal to 30 . Their length is $24 \mathrm{~mm}$ and diameter is $0.80 \mathrm{~mm}$. The steel fiber has tensile strength not less than $1000 \mathrm{MPa}$. A third generation super-plasticizer for homogenous concrete Sika@Viscocrete@-3425 was used in all concrete mixtures. Natural river sands were used as fine aggregate in the concrete mixtures with specific gravity 2.6. The coarse aggregate was dolomite with maximum size of $20 \mathrm{~mm}$ and specific gravity 2.68. fine aggregate to coarse aggregate ratio ranges from 0.37 to 0.39 . The aggregate grading is shown in Tab. 5 .

\begin{tabular}{|c|c|c|c|c|c|c|}
\hline Mix No. & $\begin{array}{c}\text { S.FUME } \\
\% \\
\text { CEMENT }\end{array}$ & $\begin{array}{c}\text { S.FIBER } \\
\%\end{array}$ & $\begin{array}{c}\text { SP } \\
\% \\
\text { CEMENT }\end{array}$ & $\mathrm{AG} \mathrm{mm}$ & $\begin{array}{c}\text { W/C } \\
\text { RATIO }\end{array}$ & $\begin{array}{c}\text { FLY-ASH } \\
\% \\
\text { CEMENT }\end{array}$ \\
\hline 1 & 0 & 0 & 0.3 & 20 & 0.27 & 0 \\
\hline 2 & 0 & 0 & 0.3 & 20 & 0.31 & 10 \\
\hline 3 & 0 & 0 & 0.3 & 20 & 0.35 & 20 \\
\hline 4 & 0 & 1 & 0.5 & 14 & 0.27 & 0 \\
\hline 5 & 0 & 1 & 0.5 & 14 & 0.31 & 10 \\
\hline 6 & 0 & 1 & 0.5 & 14 & 0.35 & 20 \\
\hline 7 & 0 & 2.5 & 0.7 & 10 & 0.27 & 0 \\
\hline 8 & 0 & 2.5 & 0.7 & 10 & 0.31 & 10 \\
\hline 9 & 0 & 2.5 & 0.7 & 10 & 0.35 & 20 \\
\hline 10 & 5 & 0 & 0.5 & 10 & 0.27 & 10 \\
\hline 11 & 5 & 0 & 0.5 & 10 & 0.31 & 20 \\
\hline 12 & 5 & 0 & 0.5 & 10 & 0.35 & 0 \\
\hline 13 & 5 & 1 & 0.7 & 20 & 0.27 & 10 \\
\hline 14 & 5 & 1 & 0.7 & 20 & 0.31 & 20 \\
\hline 15 & 5 & 1 & 0.7 & 20 & 0.35 & 0 \\
\hline 16 & 5 & 2.5 & 0.3 & 14 & 0.27 & 10 \\
\hline 17 & 5 & 2.5 & 0.3 & 14 & 0.31 & 20 \\
\hline 18 & 5 & 2.5 & 0.3 & 14 & 0.35 & 0 \\
\hline 19 & 10 & 0 & 0.7 & 14 & 0.27 & 20 \\
\hline 20 & 10 & 0 & 0.7 & 14 & 0.31 & 0 \\
\hline 21 & 10 & 0 & 0.7 & 14 & 0.35 & 10 \\
\hline 22 & 10 & 1 & 0.3 & 10 & 0.27 & 20 \\
\hline 23 & 10 & 1 & 0.3 & 10 & 0.31 & 0 \\
\hline 24 & 10 & 1 & 0.3 & 10 & 0.35 & 10 \\
\hline 25 & 10 & 2.5 & 0.5 & 20 & 0.27 & 20 \\
\hline 26 & 10 & 2.5 & 0.5 & 20 & 0.31 & 0 \\
\hline 27 & 10 & 2.5 & 0.5 & 20 & 0.35 & 10 \\
\hline
\end{tabular}

Table 3: Mix Proportions.

\begin{tabular}{lcc}
\hline \multicolumn{1}{c}{ Item } & Result & Egyptian Code of Practice \\
$\%$ Retained on Sieve No. 170 & $10 \%$ & \\
$\%$ Passing from Sieve No. & $90 \%$ & \\
170 & 95 minute & $>45$ minute \\
Initial Setting Time & 345 minute & $<600$ minute \\
Final Setting Time & $21.9 \mathrm{~N} / \mathrm{mm}^{2}$ & $>18 \mathrm{~N} / \mathrm{mm}^{2}$ \\
3 days compressive strength & $29.1 \mathrm{~N} / \mathrm{mm}^{2}$ & $>27 \mathrm{~N} / \mathrm{mm}^{2}$ \\
7 days compressive strength &
\end{tabular}

Table 4: Cement Properties Test Report 


\section{Preparation of the Specimens}

Concrete ingredients were mixed thoroughly for about seven minutes using a rotating mixer. The binder, i.e. cement, fine aggregate, coarse aggregate, SF, and FA were first mixed for 1 min without water. Afterwards, water and super-plasticizer were gradually added in $30 \mathrm{~s}$ followed by a 1 min mixing. Then $20 \%$ of steel fiber were added and mixed for 2 min. At last, all the remaining fibers were added to the flow able mortar and mixed for another 2 min to obtain a homogeneous dispersion.

\begin{tabular}{ccccc}
\hline $\begin{array}{c}\text { Sieve Size } \\
(\mathrm{mm})\end{array}$ & \multicolumn{2}{c}{ Maximum } & \multicolumn{3}{c}{ Aggregate Size $(\mathrm{mm})$} & Fine \\
20 & 100 & 100 & 100 & 100 \\
14 & 74 & 100 & 100 & 100 \\
10 & 10 & 31 & 100 & 100 \\
5 & 3 & 6 & 55 & 100 \\
2.36 & - & - & 11 & 97 \\
1.18 & - & - & - & 86 \\
0.6 & - & - & - & 48 \\
0.3 & - & - & - & 25 \\
0.15 & - & - & - & 2 \\
\hline
\end{tabular}

Table 5: Aggregate Grading (\% passing).

The slump test was performed directly after mixing and then specimens were casted and vibrated using the vibrations table. We followed the prescription of the slump test as it is mentioned in ASTM C 143-90a and BS 1881: part 102: 1983. The slump test is very useful on the site as a check on the batch-to-batch or hour-to-hour variation in the materials being fed into the mixer. Too high or too low a slump gives immediate warning and enables the mixer operator to remedy the situation. This study included 27 design mixes and the following specimens were performed in this study:

- Eighty-one cubic specimens having dimensions $100 \times 100 \times 100 \mathrm{~mm}^{3}$, three specimens for each mixture, designated for 7-day compressive strength test.

- Eighty-one cubic specimens having dimensions $100 \times 100 \times 100 \mathrm{~mm}^{3}$, three specimens for each mixture, designated for 28-day compressive strength test.

- Eighty-one cubic specimens having dimensions $100 \times 100 \times 100 \mathrm{~mm}^{3}$, three specimens for each mixture, designated for 56-day compressive strength test.

- Eighty-one cubic specimens having dimensions $100 \times 100 \times 100 \mathrm{~mm}^{3}$, three specimens for each mixture, designated for 90-day compressive strength test.

- Eighty-one cylindrical specimens having dimensions $100 \mathrm{~mm}$ in diameter and $200 \mathrm{~mm}$ in height, three specimens for each mixture, to be subjected to 28-day splitting tensile strength test.

- Eighty-one prism specimens having dimensions $100 \times 100 \times 500 \mathrm{~mm}^{3}$, three specimens for each mixture, designated for 28-day flexural strength test.

Specimens were demolded after 24 hours from casting and then stored in water until the age of testing and then mechanical tests were conducted.

\section{Testing Procedure}

To investigate the compressive strength on 7 day, 28 day, 56 day, and 90 day after casting, uniaxial compression tests were carried out. We followed BS 1881: part 108: 1983 by filling the moulds in three layers. Each layer of concrete was compacted by a vibrating table. Ramming continued until full compaction without segregation to ensure that the test result is to be representative of the properties of fully-compacted concrete. According to BS 1881: part 111: 1983, after the top surface of the cube has been finished by means of a float, the cubes were stored undisturbed for $24 \pm 4$ hours at a temperature of $20 \pm 5^{\circ} \mathrm{C}$ and a relative humidity of not less than 90 per cent. At the end of this period, the moulds were stripped and the cubes were further cured in water at $20 \pm 2{ }^{\circ} \mathrm{C}$. According to BS 1881: part 116: 1983, the loads on each cube was applied at a constant rate of stress equal to 0.2 to $0.4 \mathrm{MPa} /$ second. Also our tests conform to BS EN 12390-3. The tests were conducted by a hydraulic machine with a capacity of $3000 \mathrm{KN}$. The maximum load was recorded by a 
pointer. Splitting tensile strength was conducted using the same testing machine. Where cylindrical specimens were placed horizontally between the upper and lower bearing surfaces. In the splitting tensile strength test, we followed a rate of loading which was prescribed by ASTM C 496-90 and by BS 1881: part 117: 1983, and conform to BS EN 12390-6. The splitting test is simple to perform and gives more uniform results than other tension tests. The strength determined in the splitting test is believed to be close to the direct tensile strength of concrete 5 to 12 per cent higher.

Flexural strength tests were also carried out by means of another hydraulic testing machine with a maximum load capacity set as $50 \mathrm{KN}$ In this test, a plain concrete beam is subjected to flexure. Because the load points are spaced at one-third of the span, the test is called a third-point loading test. The theoretical maximum tensile stress reached in the bottom fibre of the test beam is known as the modulus of rupture. If fracture occurs within the central one-third of the beam, the modulus of rupture is calculated on the basis of ordinary elastic theory. Our tests conform to BS EN 12390-5 and BS 1881: part 118.

\begin{tabular}{|c|c|c|c|c|c|c|c|c|}
\hline \multirow[t]{2}{*}{ Mix No. } & $\mathrm{C} 7$ & C28 & $\mathrm{T} 28$ & F28 & C56 & C90 & PC & $S$ \\
\hline & $\mathrm{MPa}$ & $\mathrm{MPa}$ & $\mathrm{MPa}$ & $\mathrm{MPa}$ & $\mathrm{MPa}$ & $\mathrm{MPa}$ & $\mathrm{LE} / \mathrm{m}^{3}$ & $\mathrm{~mm}$ \\
\hline 1 & 18.33 & 57.98 & 3.5 & 7.27 & 55.65 & 64.15 & 915.9 & 30 \\
\hline 2 & 34.66 & 57.65 & 3.08 & 6.45 & 52.65 & 69.65 & 1637 & 40 \\
\hline 3 & 26.66 & 40.32 & 2.65 & 6.07 & 44.32 & 55.98 & 2309.5 & 40 \\
\hline 4 & 36.16 & 52.65 & 3.02 & 7.8 & 70.65 & 69.15 & 4186.1 & 40 \\
\hline 5 & 41.99 & 50.99 & 2.33 & 5.92 & 54.32 & 60.65 & 4983.2 & 40 \\
\hline 6 & 22.33 & 35.32 & 1.49 & 5.06 & 39.32 & 36.66 & 5579.9 & 100 \\
\hline 7 & 59.65 & 70.65 & 6.58 & 8.85 & 70.98 & 77.98 & 9037.5 & 150 \\
\hline 8 & 36.32 & 58.82 & 5.62 & 8.14 & 62.98 & 62.98 & 9744.5 & 100 \\
\hline 9 & 21.33 & 23.99 & 4.35 & 6.07 & 36.32 & 39.32 & 10320.2 & 80 \\
\hline 10 & 48.65 & 61.32 & 1.7 & 6.19 & 72.65 & 81.98 & 2841.9 & 100 \\
\hline 11 & 32.66 & 43.32 & 2.18 & 7 & 48.32 & 44.65 & 3396.5 & 50 \\
\hline 12 & 38.99 & 52.32 & 1.59 & 5.05 & 38.66 & 63.65 & 1507.5 & 120 \\
\hline 13 & 40.65 & 40.99 & 3.18 & 6 & 51.98 & 53.15 & 5805.7 & 70 \\
\hline 14 & 33.99 & 40.99 & 3.18 & 4.51 & 51.65 & 55.48 & 6313.6 & 150 \\
\hline 15 & 29.32 & 36.99 & 3.71 & 6.9 & 41.99 & 46.65 & 4612.2 & 50 \\
\hline 16 & 53.65 & 82.64 & 6.16 & 8.67 & 84.98 & 87.81 & 10654.8 & 30 \\
\hline 17 & 31.32 & 42.65 & 5.2 & 7.14 & 42.65 & 44.32 & 11197.9 & 20 \\
\hline 18 & 40.99 & 47.99 & 5.31 & 5.86 & 60.98 & 51.98 & 9309.7 & 30 \\
\hline 19 & 24.66 & 30.32 & 1.7 & 4.35 & 41.15 & 42.99 & 4399 & 100 \\
\hline 20 & 49.32 & 50.65 & 3.18 & 6.25 & 55.65 & 76.98 & 2336.4 & 150 \\
\hline 21 & 28.99 & 51.98 & 3.5 & 6.61 & 42.82 & 49.99 & 2857.9 & 130 \\
\hline 22 & 42.99 & 31.99 & 3.82 & 4.35 & 53.98 & 65.65 & 7911.9 & 40 \\
\hline 23 & 33.66 & 37.99 & 4.88 & 7.18 & 41.49 & 46.65 & 5539.8 & 30 \\
\hline 24 & 31.99 & 52.32 & 5.62 & 6.04 & 53.32 & 54.82 & 6104 & 150 \\
\hline 25 & 38.66 & 56.32 & 6.47 & 9.9 & 58.48 & 59.98 & 12031 & 40 \\
\hline 26 & 54.57 & 75.64 & 6.9 & 10.42 & 79.81 & 81.14 & 10029.5 & 50 \\
\hline 27 & 34.66 & 46.65 & 6 & 8.05 & 52.82 & 51.82 & 10520.5 & 50 \\
\hline
\end{tabular}

Table 6: Test results of concrete (where C7: Compressive strength at 7 days, C28: Compressive strength at 28 days, T28: Tensile strength at 28 days, F28: Flexural strength at 28 days, C56: Compressive strength at 56 days, C90: Compressive strength at 90 days, PC: Production cost, and S: Slump in $\mathrm{mm}$ ). 


\section{RESULTS AND DISCUSSION}

7 he test results on concrete specimens are shown in Tab. 6, in which compressive strength, splitting tensile strength, and flexural strength values were obtained from the average of three specimens for each of them.

The optimum possible mix proportion levels were investigated for the maximum compressive strength, splitting tensile strength, flexural strength, and slump by using Taguchi method. The 'larger the better' type of quality characteristic situation was evaluated. Also the optimum possible mix proportion levels were investigated for the minimum production cost by using Taguchi method. The 'smaller the better' type of quality characteristic situation was evaluated. The commercial software Minitab was adopted to conduct Taguchi method. The best possible mix parameter combinations of the High Strength Concrete (HSC) could be determined from the main effect plots for each response as shown in Figs. 18.

In these figures, the highest point for each factor indicates the optimal settings. Their abscissa values are the levels of parameters to choose. For Example, in Fig. 6, maximum 90 days compressive strength is obtained at $10 \%$ silica fume, $2.5 \%$ steel fiber by volume, $0.5 \%$ super-plasticizer, $20 \mathrm{~mm}$ maximum aggregate size, 0.27 water to cement ratio, and $0 \%$ fly ash. The optimal mix designs are shown in Tab. 10. As can be seen in Figs. 1-6, increasing the steel fiber content from $1 \%$ to $2.5 \%$ increased the compressive strength at 7 days, the compressive strength at 28 days, the splitting tensile strength at 28 days, the flexural strength at 28 days, the compressive strength at 56 days and the compressive strength at 90 days significantly. The reason is the bonding effect of steel fibers. Also it can be noticed that for the compressive strength at 7 days, 28 days, and 56 days, increasing the silica fume from 5\% to 10\% decreases the compressive strength for the aforementioned ages. The reason is the cement effect on strength. The compressive strength of the mix design proportion with the finest aggregate $(10 \mathrm{~mm})$ is lower, which is due to a larger specific area of fine aggregates leading to a lower flow ability of concrete.

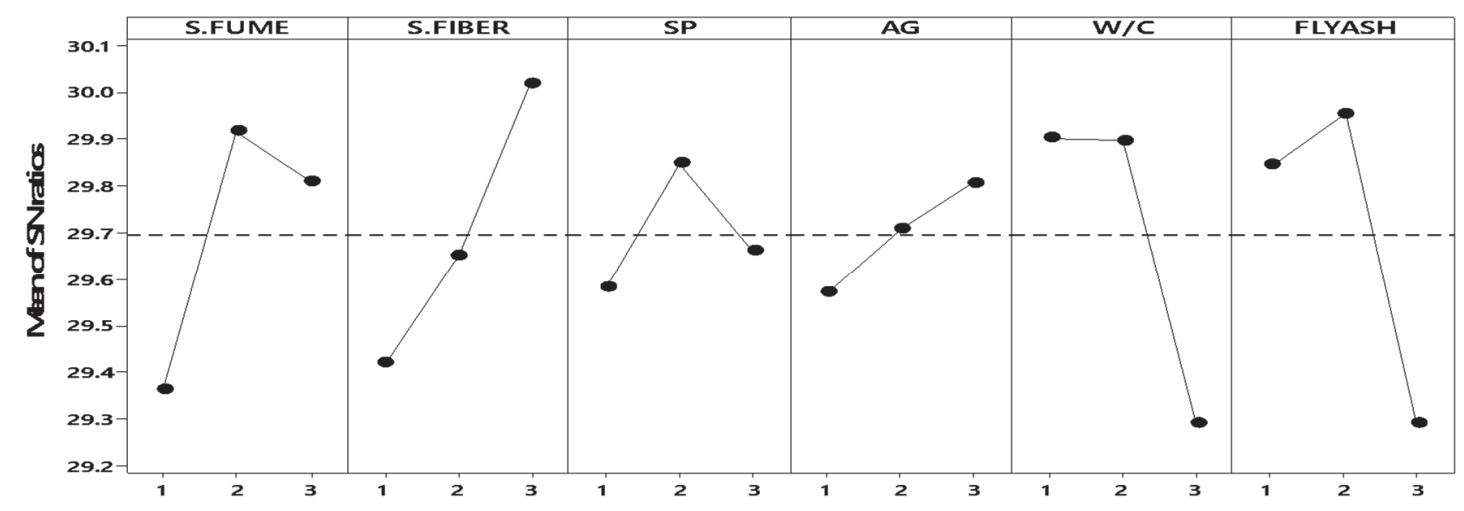

Signal-to-noise: Larger is better

Figure 1: Main effect plot for signal to noise ratio for 7 days compressive strength.

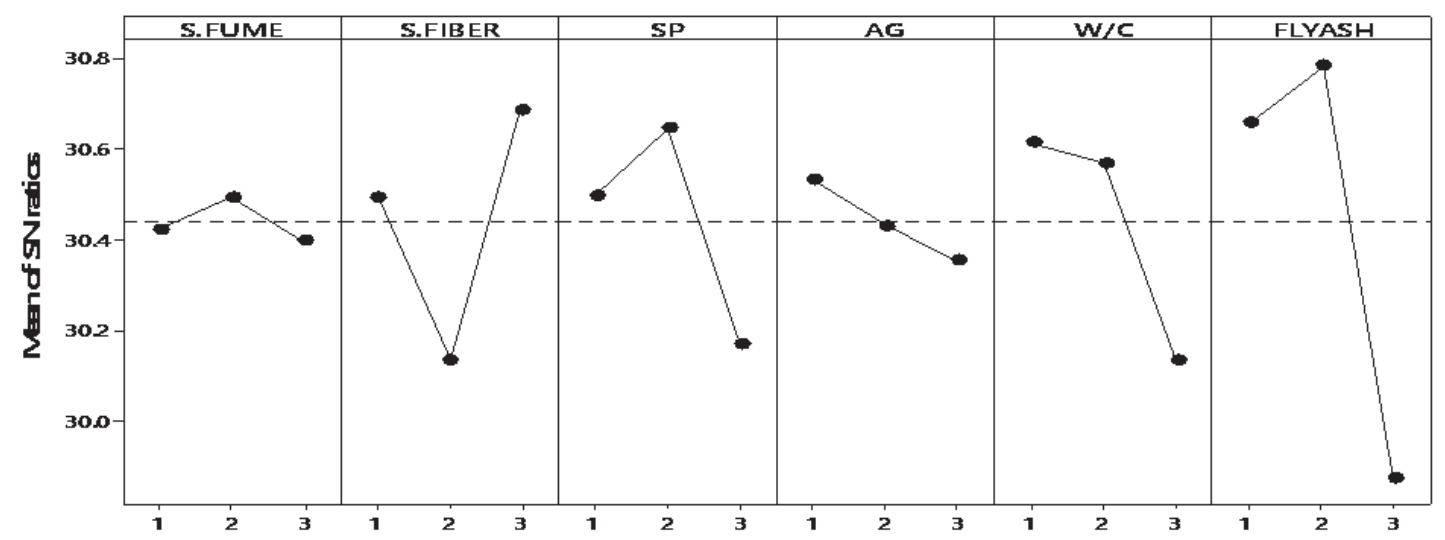

Signal-to-noise: Larger is better

Figure 2: Main effect plot for signal to noise ratio for 28 days compressive strength 


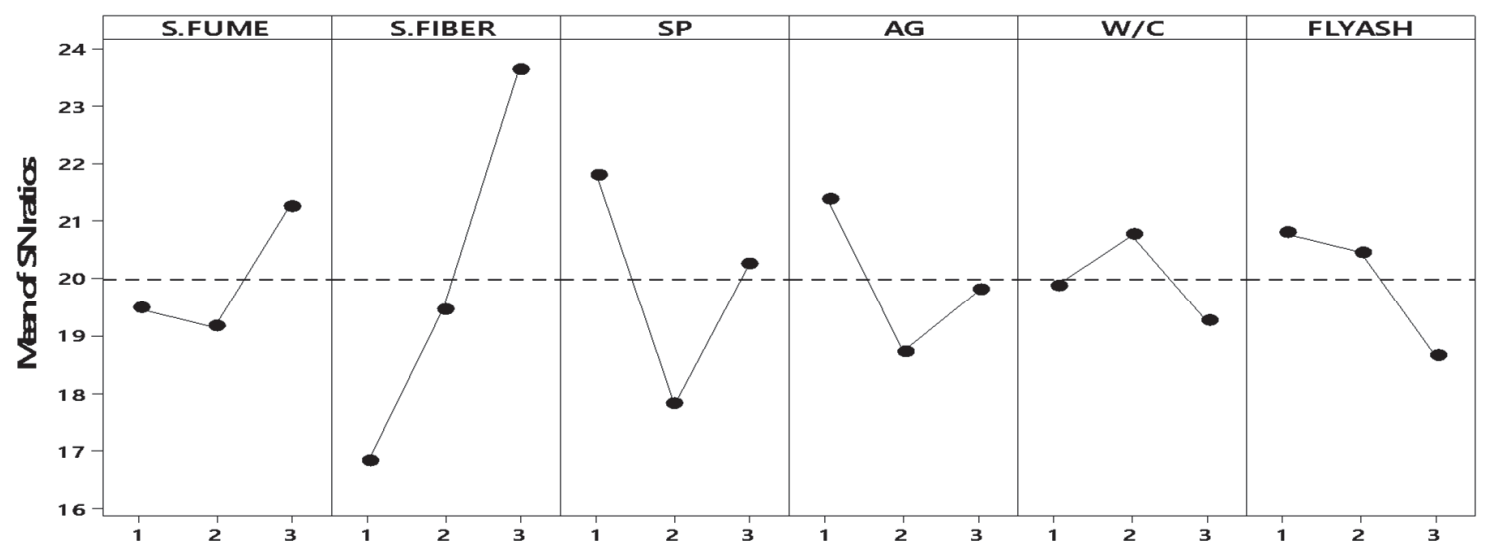

Signal-to-noise: Larger is better

Figure 3: Main effect plot for signal to noise ratio of 28 days splitting tensile strength.

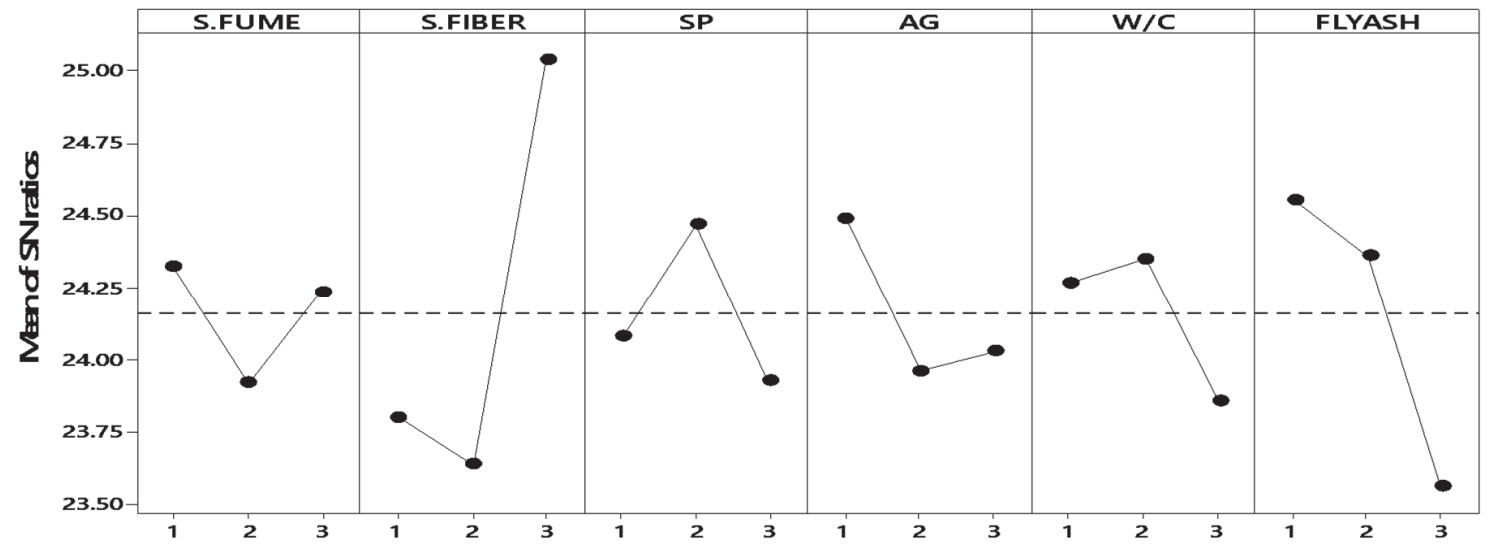

Signal-to-noise: Larger is better

Figure 4: Main effect plot for signal to noise ratio for 28 days flexural strength.

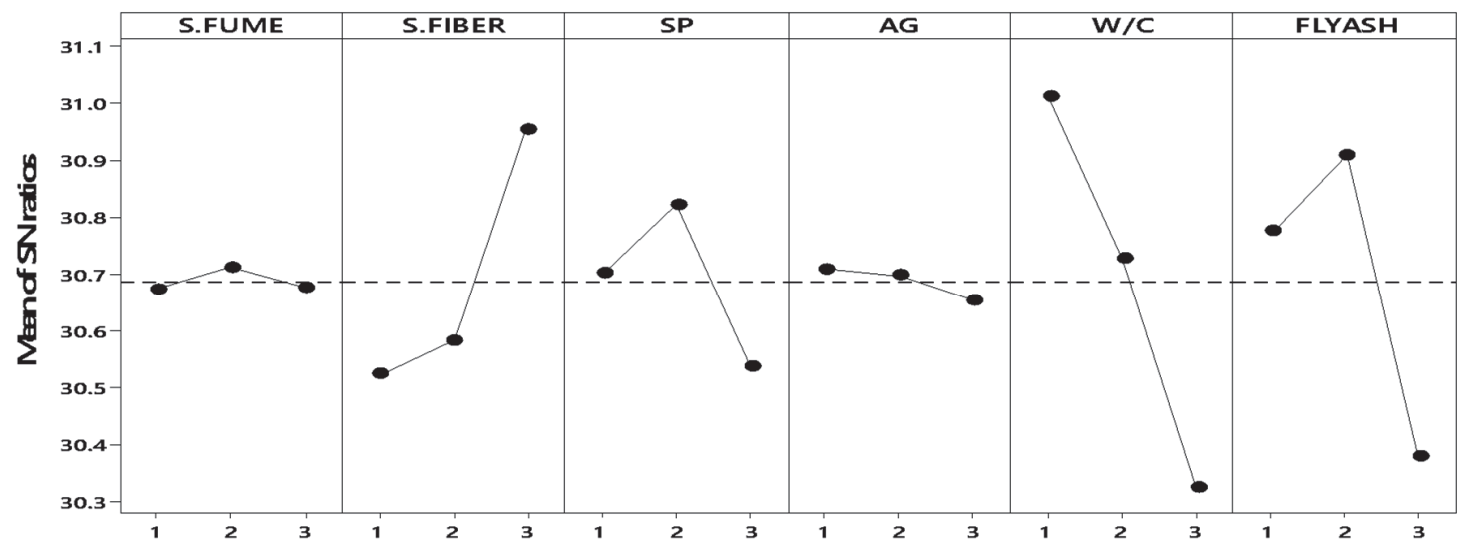

Signal-to-noise: Larger is better

Figure 5: Main effect plot for signal to noise ratio of 56 days compressive strength. 


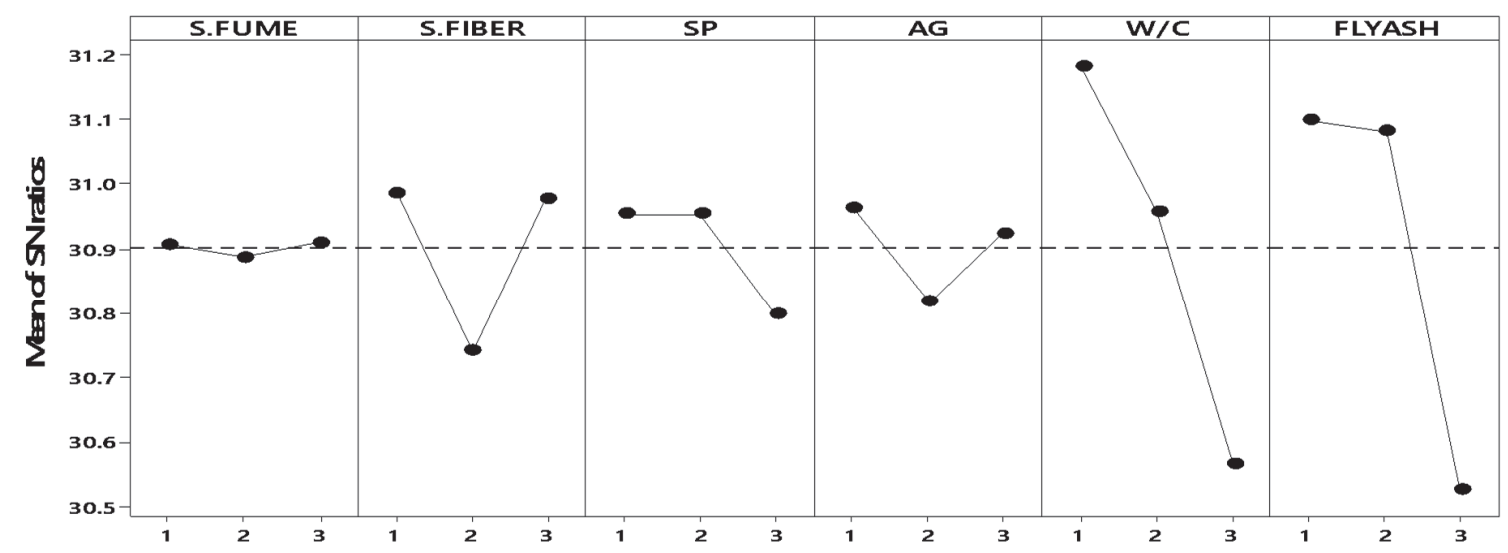

Signal-to-noise: Larger is better

Figure 6: Main effect plot for signal to noise ratio for 90 days compressive strength.

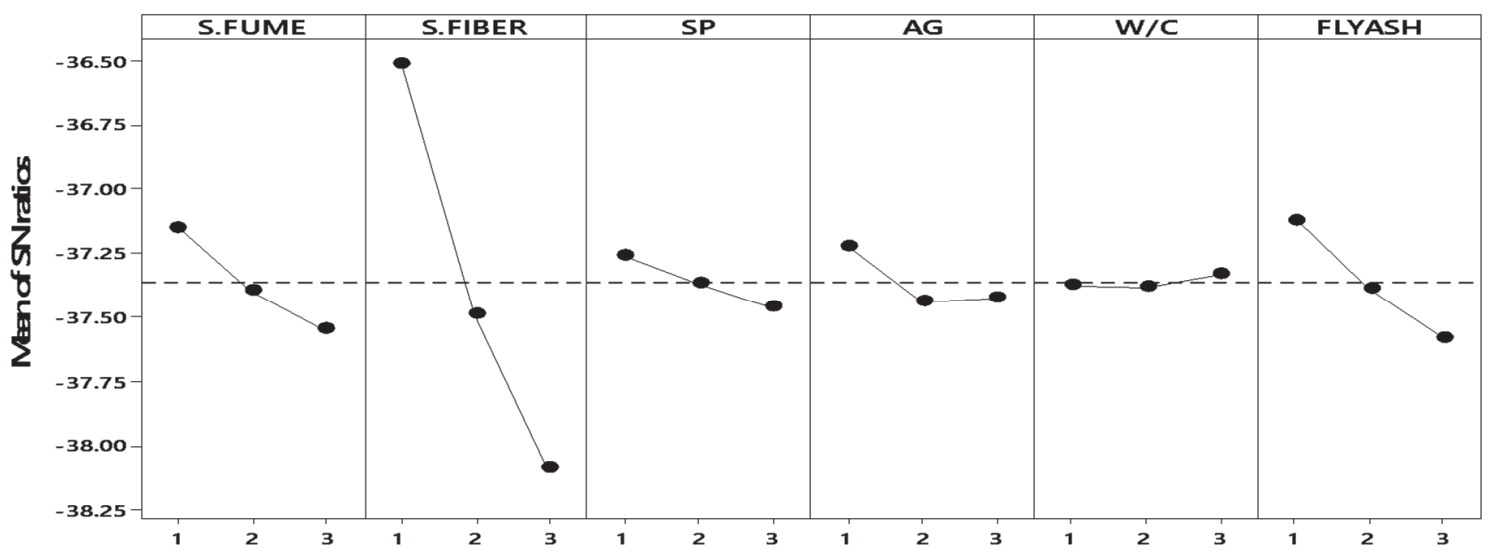

Signal-to-noise: Smaller is better

Figure 7: Main effect plot for signal to noise ratio of production cost.

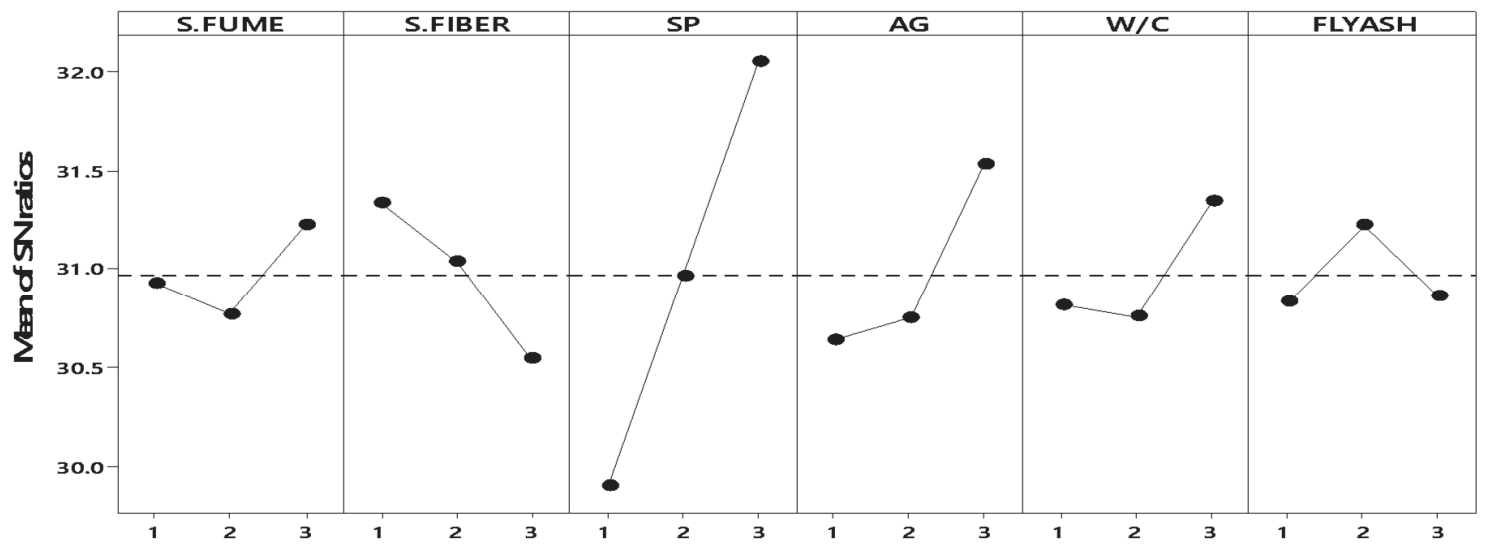

Signal-to-noise: Larger is better

Figure 8: Main effect plot for signal to noise ratio of slump. 


\begin{tabular}{ccccccc}
\hline $\begin{array}{c}\text { Optimal } \\
\text { mix } \\
\text { proportions }\end{array}$ & $\begin{array}{c}\text { Silica } \\
\text { fume }\end{array}$ & Steel fiber & $\begin{array}{c}\text { Super- } \\
\text { plasticizer } \\
\text { \%cement }\end{array}$ & $\begin{array}{c}\text { Maximum } \\
\text { Aggregate } \\
\text { Size (mm) }\end{array}$ & Water to cement ratio & Fly ash \\
C7 & 5 & 2.5 & 0.5 & 10 & 0.27 & 10 \\
C28 & 5 & 2.5 & 0.5 & 20 & 0.27 & 10 \\
T28 & 10 & 2.5 & 0.3 & 20 & 0.31 & 0 \\
F28 & 0 & 2.5 & 0.5 & 20 & 0.31 & 0 \\
C56 & 5 & 2.5 & 0.5 & 20 & 0.27 & 10 \\
C90 & 10 & 2.5 & 0.5 & 20 & 0.27 & 0 \\
PC & 0 & 0 & 0.3 & 20 & 0.35 & 0 \\
S & 10 & 0 & 0.7 & 10 & 0.35 & 10 \\
\hline
\end{tabular}

Table 7: Optimal mix design proportions for the measured quality characteristics of HSC

Percentage contribution of individual parameter can be well determined using ANOVA (Analysis of Variance). Tabs. 8 15 present the results of ANOVA. The F-test is used for comparing the factors of the total deviation. P-value indicates the significance of parameters. The contribution percentage of factors gives an idea of the significance of factors to strength, production cost, and slump. As s summary, steel fiber content and fly ash are the most influencing factors on compressive strength, splitting tensile strength, and flexural strength. Also steel fiber is the most influencing factor on production cost. For the slump the most effective factor is super-plasticizer. These are rational results.

\begin{tabular}{ccccccc}
\hline Source & DF & Seq SS & Adj MS & F-Value & P-Value & Contribution \\
S.FUME & 2 & 89.88 & 44.94 & 0.36 & 0.706 & $6.11 \%$ \\
S.FIBER & 2 & 111.03 & 55.52 & 0.44 & 0.652 & $7.54 \%$ \\
SP & 2 & 89.49 & 44.75 & 0.36 & 0.707 & $6.09 \%$ \\
AG & 2 & 175.99 & 88 & 0.7 & 0.514 & $11.95 \%$ \\
W/C & 2 & 282.77 & 141.39 & 1.12 & 0.353 & $19.20 \%$ \\
FLY & 2 & 722.94 & 361.47 & 2.87 & 0.09 & $49.11 \%$ \\
ASH & 14 & 1762.97 & 125.93 & & & \\
Error & 14 & & & & & \\
\hline
\end{tabular}

Table 8: Analysis of Variance for 7 days Compressive Strength.

\begin{tabular}{ccccccc}
\hline Source & DF & Seq SS & Adj MS & F-Value & P-Value & Contribution \\
\hline S.FUME & 2 & 150.1 & 75.07 & 1.47 & 0.263 & $3.47 \%$ \\
S.FIBER & 2 & 1175.5 & 587.77 & 11.51 & 0.001 & $27.23 \%$ \\
SP & 2 & 281.4 & 140.69 & 2.76 & 0.098 & $6.52 \%$ \\
AG & 2 & 144.6 & 72.29 & 1.42 & 0.275 & $3.34 \%$ \\
W/C & 2 & 650.3 & 325.14 & 6.37 & 0.011 & $15.06 \%$ \\
FLY & 2 & 1916.4 & 958.21 & 18.77 & 0 & $44.38 \%$ \\
ASH & & 714.7 & 51.05 & & & \\
Error & 14 & & & & & \\
\hline
\end{tabular}

Table 9: Analysis of Variance for 28 days Compressive Strength. 


\begin{tabular}{ccccccc}
\hline Source & DF & Seq SS & Adj MS & F-Value & P-Value & Contribution \\
S.FUME & 2 & 5.5882 & 2.7941 & 4.09 & 0.04 & $7.77 \%$ \\
S.FIBER & 2 & 51.709 & 25.8545 & 37.85 & 0 & $71.92 \%$ \\
SP & 2 & 5.8866 & 2.9433 & 4.31 & 0.035 & $8.19 \%$ \\
AG & 2 & 1.7363 & 0.8682 & 1.27 & 0.311 & $2.41 \%$ \\
W/C & 2 & 0.2947 & 0.1474 & 0.22 & 0.809 & $0.41 \%$ \\
FLY & 2 & 6.6807 & 3.3403 & 4.89 & 0.025 & $9.29 \%$ \\
ASH & 14 & 9.5639 & 0.6831 & & & \\
Error & 14 & & & & \\
\hline
\end{tabular}

Table 10: Analysis of Variance for 28 days Splitting Tensile Strength.

\begin{tabular}{ccccccc}
\hline Source & DF & Seq SS & Adj MS & F-Value & P-Value & Contribution \\
S.FUME & 2 & 1.393 & 0.6963 & 0.34 & 0.717 & $2.36 \%$ \\
S.FIBER & 2 & 32.935 & 16.4673 & 8.07 & 0.005 & $55.71 \%$ \\
SP & 2 & 7.375 & 3.6873 & 1.81 & 0.2 & $12.47 \%$ \\
AG & 2 & 4.335 & 2.1673 & 1.06 & 0.372 & $7.33 \%$ \\
W/C & 2 & 5.007 & 2.5037 & 1.23 & 0.323 & $8.47 \%$ \\
FLY & 2 & 8.072 & 4.0362 & 1.98 & 0.175 & $13.66 \%$ \\
ASH & 28.564 & 2.0403 & & & \\
Error & 14 & 28.03 & \\
\hline
\end{tabular}

Table 11: Analysis of Variance for 28 days Flexural Strength.

\begin{tabular}{ccccccc}
\hline Source & DF & Seq SS & Adj MS & F-Value & P-Value & Contribution \\
S.FUME & 2 & 2.72 & 1.36 & 0.01 & 0.992 & $0.12 \%$ \\
S.FIBER & 2 & 197.05 & 98.525 & 0.6 & 0.562 & $8.92 \%$ \\
SP & 2 & 94 & 47 & 0.29 & 0.755 & $4.27 \%$ \\
AG & 2 & 80.18 & 40.088 & 0.24 & 0.787 & $3.63 \%$ \\
W/C & 2 & 1019.46 & 509.728 & 3.1 & 0.077 & $46.14 \%$ \\
FLY & 2 & 815.74 & 407.871 & 2.48 & 0.119 & $36.94 \%$ \\
ASH & 14 & 2298.87 & 164.205 & & & \\
Error & 14 & & & & \\
\hline
\end{tabular}

Table 12: Analysis of Variance for 56 days Compressive Strength.

\begin{tabular}{ccccccc}
\hline Source & DF & Seq SS & Adj MS & F-Value & P-Value & Contribution \\
S.FUME & 2 & 18.01 & 9.004 & 0.07 & 0.934 & $0.79 \%$ \\
S.FIBER & 2 & 191.35 & 95.675 & 0.73 & 0.498 & $8.30 \%$ \\
SP & 2 & 54.65 & 27.327 & 0.21 & 0.814 & $2.37 \%$ \\
AG & 2 & 24.95 & 12.474 & 0.1 & 0.909 & $1.08 \%$ \\
W/C & 2 & 926.81 & 463.403 & 3.55 & 0.057 & $40.16 \%$ \\
FLY & 2 & 1092.26 & 546.132 & 4.18 & 0.038 & $47.33 \%$ \\
ASH & 14 & 1828.5 & 130.607 & & & \\
Error & 14 & & & & \\
\hline
\end{tabular}

Table 13: Analysis of Variance for 90 days compressive strength. 


\begin{tabular}{ccccccc}
\hline ource & DF & Seq SS & Adj MS & F-Value & P-Value & Contribution \\
S.FUME & 2 & 9425297 & 4712649 & 317.43 & 0 & $3.08 \%$ \\
S.FIBER & 2 & 280369997 & 140184998 & 9442.43 & 0 & $91.77 \%$ \\
SP & 2 & 14864 & 7432 & 0.5 & 0.617 & $0.00 \%$ \\
AG & 2 & 279413 & 139707 & 9.41 & 0.003 & $0.09 \%$ \\
W/C & 2 & 1213075 & 606538 & 40.85 & 0 & $0.40 \%$ \\
FLY & 2 & 14203210 & 7101605 & 478.34 & 0 & $4.65 \%$ \\
ASH & 207848 & 14846 & & & \\
Error & 14 & $205 \%$ &
\end{tabular}

Table 14: Analysis of Variance for Production Cost.

\begin{tabular}{ccccccc}
\hline Source & DF & Seq SS & Adj MS & F-Value & P-Value & Contribution \\
S.FUME & 2 & 1066.7 & 533.3 & 0.34 & 0.714 & $3.63 \%$ \\
S.FIBER & 2 & 2466.7 & 1233.3 & 0.8 & 0.47 & $8.41 \%$ \\
SP & 2 & 18866.7 & 9433.3 & 6.1 & 0.012 & $64.31 \%$ \\
AG & 2 & 5066.7 & 2533.3 & 1.64 & 0.23 & $17.26 \%$ \\
W/C & 2 & 1400 & 700 & 0.45 & 0.645 & $4.78 \%$ \\
FLY & 2 & 466.7 & 233.3 & 0.15 & 0.861 & $1.60 \%$ \\
ASH & 14 & 21666.7 & 1547.6 & & & \\
Error & 14 & & & & \\
\hline
\end{tabular}

Table 15: Analysis of Variance for Slump.

\section{Evaluation of factor effects}

\section{- Effect of Silica Fume}

The test results demonstrated that SF replacement at most levels is not clear on the compressive strength and flexural strength (Figs 1, 2, 4, 5, 6). These results are near to the results obtained by [16]. Hinislioglu et. al [16] found reduction in 7 days flexural strength of pavement concrete with $10 \%, 20 \%$, and $30 \%$ SF is $2 \%, 11 \%$, and $18 \%$, respectively. They interpret that due to their extreme fineness, the water requirement of SF is very high. Furthermore, the addition of SF to the cement matrix may result in micro-shrinkage cracking.

\section{- Effect of Steel Fiber}

As shown in Figs. 1-6, increasing the steel fiber content from $0 \%$ to $1 \%$ to $2.5 \%$ increases the compressive, splitting tensile, flexural strengths significantly. The reason was the bonding effect of steel fibers. These results were similar to certain extent to results obtained by [18] for compressive strength. From Fig. 11, Steel fiber increased the production cost of the mixes which contains it. From Fig. 12, increasing steel fiber decreased the workability significantly.

\section{- Effect of Super-plasticizer}

As shown in Figs. 1, 2, 4, 5, 6, increasing the Super-plasticizer content from 0.3 to $0.5 \%$ increases the compressive, and flexural strengths. However, further increasing from $0.5 \%$ to $0.7 \%$ the compressive strength, splitting tensile strength, and flexural strength decreased. Also it can be seen from Fig. 12 that increasing the super-plasticizer $0.7 \%$ enhanced the workability greatly as it is expected.

\section{- Effect of Maximum Aggregate Size}

The compressive strength, splitting tensile strength, and flexural strength of the mix-design proportion with the finest aggregate $(10 \mathrm{~mm})$ were lower, which might be due to a larger specific area of fine aggregates leading to a lower flowability of concrete. These results were similar to the test results obtained by [18].

\section{- Effect of Water / cementitious materials}

The effect of W/C ratio on the compressive strengths, splitting tensile strength, and flexural strength are shown in Figs. 16. According to ANOVA, water contents affects significantly on the properties of concrete (Tabs. 8 to 15). It has been known that compressive strength, splitting tensile strength, and flexural strength vary inversely with the $\mathrm{W} / \mathrm{C}$ ratio for 
concrete [19]. In another word, while W/C ratio decrease strength of concrete increase. From the test results, first level of $\mathrm{W} / \mathrm{C}$ ratio $(0.27)$ maximizes the $\mathrm{S} / \mathrm{N}$ as it is expected.

\section{- Effect of Fly Ash}

The effect of FA on compressive strength, splitting tensile strength, and flexural strength is given in Figs. 1-6. Test results showed that after 10\% replacement of FA the strength development decreases. Also test results for splitting tensile strength, flexural strength, and compressive strength at 90 days showed that all levels of FA replacement decreased aforementioned strengths when compared with control concrete.

\section{CONCLUSIONS}

1- An experimental study was carried out to optimize the mix design proportions for High Strength Concrete (HSC) so as to maximize the compressive strength at 7, 28, 56, 90 days, splitting tensile at 28 days, flexural strength at 28 days and slump. Mix Proportions are also set to minimize production cost. Taguchi method with $\mathrm{L}_{27}$ orthogonal array was used to investigate the ranking of different HSC parameters. The most important parameters affecting all the three mechanical properties were steel fiber, fly ash, and water to cement ratio respectively.

2- After analyzing the results, it was found that higher maximum aggregate size yielded better strength.

3- It is found that super-plasticizer is the most effective parameter for the slump.

4- The effect of the steel fiber on the strength does not appear at early ages.

5- Steel fiber is the most effective factor on splitting tensile strength and flexural strength.

6- Steel fiber is the most effective factor on production cost.

7- The strength of fly ash concrete will depend on whether a water reduction is achieved, plus the pozzolanic performance of the cement/fly ash combination. Fly ash is able to reduce the heat of hydration very effectively. Using fly ash in concrete will increase the setting time compared with an equivalent grade of PC concrete. This increased setting time reduces the rate of workability loss. Formwork striking times at lower ambient temperatures may have to be extended in comparison to PC concrete.

8- Fly ash is the most effective factor on compressive strengths at all ages. This does not mean increase the strengths but FA replacement decreased the strengths.

9- High strength is generally the first property associated with silica fume concrete. An increase in the compressive strength using silica fume will result in a similar relative increase in the tensile and flexural strength. This plays a strong role when silica fume concrete is used in flooring, bridging or roadway projects.

10- The inclusion of silica fume in concrete causes significant changes in the structure of the matrix, though both physical action and a pozzolanic reaction, to produce a densified, refined pore system and greater strength.

11- The Study showed that Taguchi method can be used effectively and economically for designing the experiments and for determining the optimum process parameters.

\section{REFERENCES}

[1] Alam, S., Fatima, A. and Butt, M.S. (2007). Sustainable development in Pakistan in the context of energy consumption demand and environmental degradation, Journal of Asian Economics, 18(5), pp. 825-837.

[2] Singh, R.K., Murty, H.R., Gupta, S.K. and Dikshit, A.K. (2009). An overview of sustainability assessment methodologies, Ecological Indicators, 9(2), pp. 189-212.

[3] WCED (1987), Our common future, report of the World Commission on Environment and Development, World Commission on Environment and Development.

[4] Wang, J.-J., Jing, Y.Y., Zhang, C.F. and Zhao, J.H. (2009). Review on multi-criteria decision analysis aid in sustainable energy decision-making, Renewable and Sustainable Energy Reviews, 13(9), pp. 2263-2278.

[5] Kleindorfer, P.R., Singhal, K. and Wassenhove, L.N. (2005). Sustainable operations management,Production and Operations Management, 14(4), pp. 482-492.

[6] Bansal, S., Biswas, S. and Singh, S.K. (2017). Fuzzy decision approach for selection of most suitable construction method of Green Buildings, International Journal of Sustainable Built Environment, 6(1), pp. 122-132.

[7] Govindan, K., Shankar, K.M. and Kannan, D. (2016). Sustainable material selection for construction industry - a hybrid multi criteria decision making approach, Renewable and Sustainable Energy Reviews, 55, pp. 1274-1288.

[8] Aitcin, P-C. (2004) High Performance Concrete, Taylor \& Francis e-library, ISBN 0-203-78327-1. 
[9] Gordon, J. E. (1991). Structures or why things don't fall down, Penguin Books, London, ISBN 01401.3628 2, 174 PP.

[10] Ozbay, E, Oztas, A, Baykasoglu, A, Ozbebek, H. (2009). Investigating mix proportions of high strength selfcompacting concrete by using Taguchi method, Construction and Building Materials, 23, pp. 694-702.

[11] Khiabani, A.C., Bastami, M., Baghbadrani, M., Kordi, M. (2011). Optimization of the Concrete Mix Proportions Centered on Performance After Exposure to High Temperature, Advanced Materials Research, 268-270, pp. 372-376.

[12] Hashemi, S.H., Soleymani, A. (2013). Optimization of HSC Compressive Strength by Taguchi Method, Applied Mechanics and Materials, 253-255, pp. 572-575.

[13] Emara, M.A., Eid F.M., Nasser A.A., Safaan M.A. (2018). Prediction of Self-Compacting Rubberized Concrete Mechanical and Fresh Properties using Taguchi Method, J. of Civil \& Environmental Engineering, 8(2).

[14] Kumari, S., Palamu, T. (2013). Optimization of Cement Content in Concrete using Additives, $3^{\text {rd }}$ International Conference on Sustainable Construction Materials and Technologies, http://www.claisse.info/Proceedings.htm.

[15] Tan, O., Zaimoglu, A. S., Hinislioglu, S., Altun S. (2005). Taguchi approach for optimization of the bleeding on cement -based grouts, Tunneling and Underground Space Technology, 20, pp. 167-173.

[16] Hinislioglu, S., Bayrak, O. U. (2004). Optimization of Early Flexural Strength of Pavement Concrete with Silica Fume and Fly Ash by the Taguchi Method, Civil Engineering and Environmental Systems, 21(2), pp. 79-90.

[17] Kackar, R.N. (1986). Taguchi's Quality Philosophy : Analysis and Commentary, American Society for Quality Control.

[18] Ye, L., Hai, T.K., Dong, Z. (2016). Optimization of Compressive Strength and Tensile Strength of Ultra-High Performance Concrete, HiperMat Proceedings, Kassel, Germany.

[19] Bayrak, O.U., Hattatoglu, F., Hinislioglu, S. (2010). Determination of Modulus of Rupture of Pavement Concrete with Silica Fume and Fly Ash using Taguchi Technique, International Journal of Civil and Structural Engineering, $1(3)$.

[20] Neville, A.M. (2002). Properties of Concrete, British Library, ISBN 0-582-23070-5.

[21] Kaliyan Mathiyazhagan, A., Gnanavelbabu, B., Lokesh Prabhuraj (2018). A sustainable assessment model for material selection in construction industries perspective using hybrid MCDM approaches, Journal of Advances in Management Research.

[22] Behera, M., Bhattacharyya, S.K., Minocha, A.K., Deoliya, R. and Maiti, S. (2014). Recycled aggregate from C\&D waste and its use in concrete - a breakthrough towards sustainability in construction sector: a review, Construction and Building Materials, 68, pp. 501-516. 